\title{
The Position and Role of Traditional Chinese Painting in the Tea Culture
}

\author{
Wenxiu Li \\ School of Art and Design \\ Huanghe Science and Technology College \\ Zhengzhou, China
}

\begin{abstract}
Chinese painting and Chinese tea culture both are the important parts of Chinese traditional culture, and have a long history. Throughout their development, they have become the typical representatives of Chinese trademark culture. Between the development of Chinese painting and that of Chinese tea culture, there is indispensable connection and integration. This author expounds the position and role of Chinese painting in the development of Chinese tea culture around the coherence and indivisibility between them, and hopes to give the valuable reference.
\end{abstract}

Keywords-Chinese painting; tea culture; position

\section{INTRODUCTION}

Chinese painting and Chinese tea culture both are the typical representatives of Chinese traditional culture. They both have a long history. In the long history of several thousand years in China, they affect each other with certain coherence and inseparability, make progress and deposition together. Painting, comes from life, but is far beyond the ordinary meaning of life, and has become the carrier of the scholars and poets to express their mind and ambition in the history. Chinese tea ceremony with its quiet, delicate and elegant texture, since its birth, has been an integral part of the diet in the daily life of tea-drinking people. At the same time, Chinese painting in the tea culture has its unique position and influence, and with its value and function, Chinese painting can make China tea culture have more abundant meaning and connotation to a large extent, so that it has a far-reaching influence at home and abroad.

\section{The Position of Chinese PAinting IN THE TEA CULTURE}

\section{A. The Coherence of Chinese Painting and Tea Culture}

Whether it is tea-drinking people, or the painters, they both have a "most refinement" attitude. Liu Yu once said in his book The Classic of Tea: the tea can be used for drinking, due to its cold and bitter flavor, it is most appropriate for the people who have fine behavior and thrifty virtue. He incisively and vividly expressed the "excellence" of the tea-drinking people, which is detailed and even involves the tea tree growth environment and the best tea-picking season and tea-making laws. The detailed knowledge of tea furthest shows the fine attitude of the tea-drinking people. The great poet Bai Juyi in the Tang Dynasty also said in his poem: "the rope-made bed is set here, cleaning teapot near it, the ceramic white ware is very clean, the red furnace carbon is flaming." This poem specifically described the tea details of Bai Juyi, regardless of the appliance used for holding tea or the fuel for cooking the tea, they are extremely dainty: the cleaned "ceramic white ware" is used for holding the tea, and the best quality "charcoal" is used to boil the tea. Regardless of Lu Yu or Bai Juyi, from their each word, we can know that the fine attitude of tea-drinking people. Likewise, Chinese painting and tea matters show the high coherence, which is also the pursuit of painting activities for the fine attitude. Guo $\mathrm{Xi}$, the painter in the Northern Song Dynasty once described in his The Elegance of the Bamboo and Spring: once starting to draw, certainly clean room and furniture, make incense around, prepare fine brush and ink, wash hands and clean ink stone, like meeting great guests, and keep self relaxing and calm, then begin painting. This is particular about, not treated lightly! From his poem, it can be clearly seen that it must be "whist" for painting activity. In conclusion, we can find that the painters have formed the painting attitude, which is highly compatible with the tea drinkers' tea-drinking attitude, keeping the pursuit of "excellence". At the same time, it also reflects the traditional Chinese painting has a very important position in the tea culture.

\section{B. The Dependence of Tea Matter and Painting on Water and the Close Relationship between Both Them}

Regardless of painting or tea matter, they have a common dependency, which is water. Water is the source of all things. Laozi in his Tao Te Ching once said: as good as water, benefiting everything without conflict or resistance. From his statement, we can deeply be aware of the wisdom and tolerance of the water. The tea, we often talk about, specifically refers to the interaction of water and tea, while Chinese painting is also produced from the mutual blending of ink and water. Regardless of tea or Chinese painting, their formation and birth have inseparable relationship with the water. In the viewpoint of tea, just as the truth of "tea property must be from water", if there is not the processing of water, the best quality tea can't show its aroma, color and taste. For the importance of water for tea, both Xiong Mingyu's Jieshan Tea Record and Zhang Dafu's Viewpoint on Plume Blossom remarkably mention it. Water for the painting, is equally important, and has a very important and indispensable role. 
The common effect of water and ink forms the so-called Chinese painting. Jing Hao once in his Brushwork Record mentioned that "there are six essentials in my painting", in which, the ink refers to the ink color effect after blending of water and ink. Ink does not have its own color ink, but it has the so-called ink color under the action of water. Modern Fan Ceng, the painting master also said: "water is the life of Chinese painting." His words also illustrate the indispensable role and value of water in Chinese painting. From the dependence of painting and tea matter on water, Chinese painting has the indispensable important position in the tea culture.

\section{Chinese Painting and Tea Essentially have the Same Pursuit of "Harmony"}

No matter for the painting, or for the tea ceremony, they have a common essential pursuit, that is "harmony". "Harmony" in Chinese culture refers to the unity of the diversity or the unity of the contrariety. In ancient China, it is embodied in the theory of numerous philosophies. "Harmony" in the Confucianism refers to the social harmony, and in the Taoist thought refers to the harmony between human and the nature, and in the Buddhist thought, refers to the harmony between human and the mind. For the tea culture in Chinese traditional culture and the Chinese painting, they both are deeply under the influence of Chinese traditional philosophy. $\mathrm{Lu} \mathrm{Yu}$ in his creation of Book of Tea incisively represents the thought of "harmony" for the tea ceremony in the most whole tea boiling period; from his point of view, he felt the water for tea should be in a state of "a series of spring bead", rather than of "fish eyes" of " surging spoondrift", because the water in the state of "a series of spring bead" just reflects his pursuit of "harmony" in tea ceremony. In the Tang Dynasty, Pei Wen recorded in his Narration of Tea: "tea, originated from Jin Dynasty, popular in this dynasty, is clear, its sexual fine, its taste Hao Jie, the use of Di Fan, has highly clear quality and rich and pure taste; it can eliminating troubles and achieve placidity." Here he specifically described the function of tea, where the "achieve placidity" just embodied the reconciliation of tea, and further reflected the pursuit of "harmony" in tea culture. In the perspective of Chinese painting, it has the same pursuit of "harmony" as that in the tea culture, and it pursues the state "between similarity and dissimilarity". Qi Baishi, the modern Chinese painting master once said: "The charm of the painting is between similarity and dissimilarity. The extreme similarity is vulgar and the dissimilarity is deceiving". The state "between similarity and dissimilarity" in his words referred to the essential pursuit of "harmony" in Chinese painting. At the same time, the whole layout of traditional Chinese painting, has been following the concept of "in the sparse place can horse gallop, and in the thick place cannot air enter". Here the "sparse" and the "thick" is opposites, but they present a delectable neutral beauty, fully showing the essential pursuit of "harmony". In conclusion, regardless of Chinese painting or Chinese tea culture, they all have the same pursuit: Harmony. It also illustrates the important position and influence of Chinese painting in Chinese tea culture.

\section{The Role of Chinese Painting In the TeA Culture}

\section{A. Chinese Painting Promotes the Tea Culture in the Form of Painting}

Throughout China' long history of several thousand years, all dynasties have their painting works based on tea matter, such as the Play Musical Instrument and Sip Tea created Zhou Fang in the Tang Dynasty, and Lu Quan Making Tea and Grinding Tea created by Liu Songnian in the Southern Song Dynasty, and Making Tea and Tea Fight created by the painter Zhao Mengfu in the Yuan Dynasty, which all take the tea matter as the creation theme. The emergence of tea painting theme undoubtedly largely enriches the theme of the painting, while from the perspective of Chinese painting, the emergence of Chinese painting, especially the Chinese paintings with tea matter as the center theme, has a more important role in furthest making the tea publicity through the excellent painting works. Chinese paintings are famous at home and abroad, favored by the numerous painting fans, and with the huge influence of Chinese painting, Chinese tea culture is unguardedly spread to the wider scope and field, so that the people who love the paintings can be aware of the excellence and profundity of Chinese tea culture. From this point, Chinese painting plays an important role in the inheritance and extension of Chinese tea culture.

\section{B. Chinese Painting Records the Development of Tea Culture in the Form of Painting}

From the value of painting, painting can promote the progress of the tea matter to a certain extent. In the picture of the Col Tea Record drawn by Feng Kebin in the Ming Dynasty, 13 kinds of appropriate tea are proposed, of which a kind of tea named as "Huihan", specifically means that it is appropriate to create a painting when drinking tea, and it reflects the role and value of painting. At the same time, when creating a Chinese painting, the tea matter as a theme can be recorded specifically and clearly, including the changes of the tea matter and the real development of tea in a certain period, playing the role of history chart. For example, the painting of Grinding Tea created by Liu Songnian, the famous painter in the Tang and Song Dynasties, described the specific process of grinding tea before drinking tea cake in the Tang and Song Dynasties. Compared with the popular literal records of tea, such a record in the form of painting is more vivid and concrete. The tea matter record in the form of Chinese painting can make more people to bear in mind the tea matter of different times. Therefore, traditional Chinese painting also plays a certain role of promotion and history chart in the tea culture.

\section{CONCLUSION}

In conclusion, we can find that there is a close connection between Chinese painting and Chinese tea culture. Chinese painting often uses very simple and unadorned ink and color to set off the colorful connotation and meaning, just like the tea seeking for the noble elegant state in a modest attitude. Chinese painting is closely linked with tea culture and shows a great coherence and indivisibility, so that we can find that the Chinese painting plays a very important and indispensable role in the Chinese tea culture. At the same time, in its development 
and progress, Chinese painting also plays a certain role in the Chinese tea culture, not only spreading Chinese tea culture, but also playing the role of tea culture history chart, recording the specific tea culture development of every period, providing more vivid evidence for the successors to make acknowledgement and comprehension of it.

\section{REFERENCES}

[1] Li Yang: The application of Chinese painting elements in the custom clothing design [D]. Beijing institute of fashion technology, 2012.

[2] Bao Hong: image semantic research on the Automatic classification of visual perceptive Chinese painting [D]. Beijing Jiaotong University, 2012.

[3] Hui Lan: The formation of two major ways of Chinese painting modern transformation [D]. China academy of fine arts, 2004.

[4] Zhao Xia: Characteristic research on the art performance in Chinese painting [D]. Ludong University, 2014.

[5] He Wenjun: Research on accepting foreign art influence five times by Chinese painting [D]. Tianjin University, 2012.

[6] Yu Yue: Contemporary history of Chinese tea culture research and future tendency [J]. Jiangxi Social Sciences 2005: 7 to 18.

[7] Xiang Zongzhou: The influence of tea culture on tea brand construction [D]. Chinese Academy of Agricultural Sciences 2013.

[8] Tan Zhen: The tracing historical source of Chinese tea culture and overseas communication [D]. Qingdao Technological University, 2014.

[9] Zhang Xinyu: The promotion and development of tea culture [D]. Qingdao University, 2012. 